2. North M. Hippocratic Oath. Bethesda (MD): National Library of Medicine; 2002. Available: www. nlm.nih.gov/hmd/greek/greek_oath.html (accessed 2015 Apr. 24).

3. Mortier T, Leiva R, Cohen-Almagor R, et al Between palliative care and euthanasia. J Bioeth Inq 2015;12:177-8.

4. Bolt EE, Snijdewind MC, Willems DL, et al. Can physicians conceive of performing euthanasia in case of psychiatric disease, dementia or being tired of living? J Med Ethics 2015 Feb. 18 [Epub ahead of print].

5. Sheldon T. Mobile "life's end" teams start work in Netherlands. BMJ 2012;6:e1681.

CMAJ 2015. DOI:10.1503/cmaj.1150044

\section{Pocketbook versus patient}

We read with interest the systematic review by Jenkins and colleagues. ${ }^{1}$ Yes, imaging is sometimes overused and is a substantial financial cost for our publicly funded health care system. ${ }^{2,3}$ However, we question the utility of assessing interventions by measuring reductions in imaging referral rate. This yields information pertinent to costsavings and does little toward balancing patient care. Referral rates are a poor surrogate for the more important and relevant outcomes of imaging appropriateness and patient-important outcomes (i.e., diagnostic yield and subsequent treatment outcomes).

An Ontario Ministry of Health bulletin, disseminated to all physicians in June 2012 stated that:

OHIP payment eligibility will continue to be limited to services that are medically necessary to the individual patient's circumstances, informed by the best available evidence. New language has been added to the Schedule of Benefits for Physician Services noting that studies of the lumbar spine should not be routinely ordered or rendered without suspected or known pathology ... If the diagnostic services were found to be not medically necessary in accordance with $\mathrm{s}$. 18.2(1) and 18.2(2) of the Health Insurance Act, the physician requesting the diagnostic services will be responsible for repayment. ${ }^{4}$

Such an aggressive approach to reducing referral rates remains unparalleled in Canada. Threats of financial retribution against referring physicians are a dangerous precedent and could make physicians reluctant to order imaging regardless of whether it is needed. Such decisions would not be guided by concern for the patient but by the desire for cost-savings. This approach was shown to be ineffective in reducing referral rates. ${ }^{5}$
Though costly, imaging undoubtedly has value. We should not be guided by evidence conceived with cost-savings in mind but by evidence based on patient-important outcomes.

\section{Sean A. Kennedy MD, Mark $\mathrm{O}$.}

\section{Baerlocher MD}

Diagnostic Radiology Residency Program

(Kennedy), University of Toronto, Toronto, Ont.; Department of Radiology (Baerlocher), Royal Victoria Hospital, Barrie, Ont.

\section{References}

1. Jenkins HJ, Hancock MJ, French SD, et al. Effectiveness of interventions designed to reduce the use of imaging for low-back pain: a systematic review. CMAJ 2015;187:401-8.

2. Tu JV, Pinfold SP, McColgan P, et al. Access to health services in Ontario. ICES Atlas 2e. Toronto: Institute for Clinical Evaluative Sciences; 2006.

3. Busse J, Alexander, PE, Abdul-Razzak A, et al. Appropriateness of spinal imaging use in Canada. Ottawa: Canadian Institutes of Health Research; 2013.

4. Ontario Health Insurance Plan: OHIP bulletins: physician services. Toronto: Ministry of Health and LongTerm Care; 2015. Available: www.health.gov.on.ca/ en/pro/programs/ohip/bulletins/4000/bulletin_4000_ mn.aspx (accessed 2015 Apr. 12).

5. Kennedy SA, Fung W, Malik A, et al. Effect of governmental intervention on appropriateness of lumbar MRI referrals: a Canadian experience. $J$ Am Coll Radiol 2014;11:802-7.

\section{CMAJ 2015. DOI:10.1503/cmaj.1150045}

\section{Social equity in health care}

Wong and colleagues observe two interesting and unfortunate findings in their study. ${ }^{1}$ Individuals at higher risk of poor outcomes, including those with more comorbidities, are less likely to receive follow-up care, and those who visited a physician in the preceding year were more likely to receive follow-up care. This important work shows that medical need does not determine who receives follow-up care in a Canadian setting. Sicker patients may be less likely to see a physician for follow-up because of their "underlying conditions and the resulting restrictions in activity." Those who had not seen a

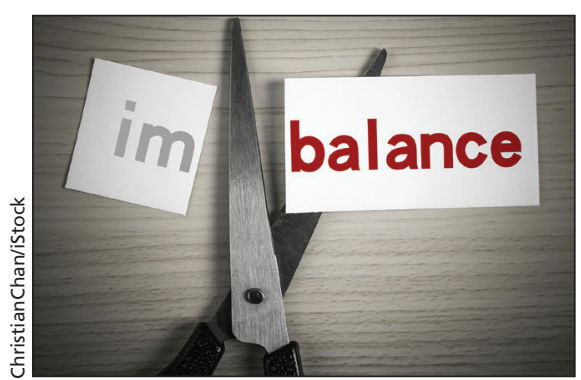

physician in the previous year represent a "vulnerable population."

There may be a more fundamental cause that could explain, in part, both primary findings. In 1971, Julian Tudor Hart, a Welsh general practitioner, proposed the "inverse care law," which states, "the availability of good medical care tends to vary inversely with the need for it in the population served." The social determinants of health (when poverty and marginalization make people sicker) are largely the same as the social determinants of health care (when the same factors make good care harder to access). As a result, individuals who need care the most are least likely to get it, even in a publicly funded system..$^{3-7}$

We appreciate the authors' conclusions, which advocate identifying and proactively retaining patients most likely to be lost to follow-up. We encourage readers to consider these findings at the level of our society and health care system.

If we want a system that effectively prioritizes and responds to medical need, it might be necessary to engage the underlying social, political and economic factors that determine who gets sick and who gets good care. In doing so, an effective health care system would also be a fair one, and a force for social equity.

Thomas D. Brothers BA, Matthew J. To BMSc, Colin Van Zoost MD, Jeffrey

Turnbull MD

Dalhousie University (Brothers, To, Van Zoost), Halifax, NS; The Ottawa Hospital (Turnbull), Ottawa Ont.

\section{References}

1. Wong MK, Wang JT, Czarnecki A, et al. Factors associated with physician follow-up among patients with chest pain discharged from the emergency department. CMAJ 2015;187:E160-8.

2. Hart JT. The inverse care law. Lancet 1971;1:405-12.

3. Watt G. The inverse care law today. Lancet 2002 ; 360:252-4

4. McBride D, Hardoon S, Walters K, et al. Explaining variation in referral from primary to secondary care: cohort study. BMJ 2010;341:c6267.

5. Hwang SW, Bugeja AL. Barriers to appropriate diabetes management among homeless people in Toronto. CMAJ 2000;163:161-5.

6. Mercer SW, Watt GCM. The inverse care law: clinical primary care encounters in deprived and affluent areas of Scotland. Ann Fam Med 2007;5: 503-10.

7. Barnett K, Mercer SW, Norbury M, et al. Epidemiology of multimorbidity and implications for health care, research, and medical education: a cross-sectional study. Lancet 2012;380:37-43. 